\title{
ARTIGOS
}

\section{TENTATIVA DE AVALIAÇÃO DO PROGRAMA ESPECIAL DE CONTROLE DA ESQUISTOSSOMOSE (PECE) NO ESTADO DA PARAÍBA, BRASIL}

\section{José Rodrigues Coura, Maria Zélia Goes de Mendonça e Joāo Pequeno Madruga}

Foi feita uma tentativa de avaliação do Programa Especial de Controle da Esquistossomose (PECE) do Ministério da Saúde do Brasil, desenvolvido pela SUCAM no Estado da Paraiba, a partir de 1976. Foram tomadas como base as 5 primeiras avaliaçōes do Programa de 1978 a 1983 e posteriormente em 1984/85 realizados exames quantitativos de fezes em uma amostra de 9.155 individuos exame clinico em 1.036 positivos, em 3 municipios selecionados nas principais regióes hidrográficas, onde o programa vem sendo realizado.

As 5 primeiras avaliaçóes realizadas pela SUCAM de 1978 a 1983 nos 47 municípios trabalhados, 23 na região do Mamanguape, 18 na região do Paraíba, 5 na região Litoral Sul e um na região do Curimataú, demonstraram uma queda da prevalência média inicial da esquistossomose de $28 \%$ para $4,9 \%$ na região do Mamanguape, de 20,9\% para 5,9\% na região do Paraíba, de 40,2\% para $18,9 \%$ na região Litoral Sul e de 4,9 para 1,4\% na região do Curimataú. Em nivel de localidade, entretanto, permaneciam com prevalência igual ou superior a 20\%, 36(10,9\%) das 329 avaliadas na região do Mamanguape, 40(13,6\%) das 293 na região do Paraíba e 43 $(47,2 \%)$ das 91 da região Litoral Sul.

Nos municípios tomados como amostra para exame clínico e quantitativo de fezes no ano de 1985 verificou-se que em Cuitegi, na região do Mamanguape, dos 3.494 examinados $154(4,4 \%)$ eliminavam em média 123 ovos de $\mathrm{S}$. mansoni por grama de fezes, nenhum tinha a forma hepatoesplênica e 20(12,9\%) tinham figado palpável. Em Mari, na regiāo do Paraiba, dos 3.735 examinados 410 (10,9\%) estavam positivos eliminando em média 165,9 ovos de $\mathrm{S}$. mansoni por grama de fezes; apenas um $(0,24 \%)$ tinha a forma hepatoesplênica e 48 (11,7\%) tinham figado palpável. Em Alhandra, na região Litoral Sul, dos 1.926 examinados 472 (24,5\%) eliminavam em média 115,4 ovos de S. mansoni por grama de fezes, 3,6\% eram hepatoesplênicos e $81(17,1 \%)$ tinham figado palpável. Em estudo anterior realizado na sede desse municipio em 1979, $24,2 \%$ da população era positiva, eliminando em média 211 ovos de S. mansoni por grama de fezes, 2,4\% tinham a forma hepatoesplênica e apenas $3 \%$ tinham figado palpável.

Palavras chaves: Esquistossomose. Controle. Tratamento em massa. Paraiba.

O programa Especial de Controle da Esquistossomose (PECE) do Ministério da Saúde foi iniciado em 1976 em 8 estados do Nordeste do Brasil, com o objetivo de eliminar a transmissão e reduzir a prevalência da infecção pelo Schistosoma mansoni a menos de $4 \% 4$.

As medidas de controle incluiam o tratamento da população com oxamniquine, aplicação periódica de moluscicidas em lugares de transmissão epidemio-

Trabalho do Departamento de Medicina Tropical do Instituto Oswaldo Cruz, do Núcleo de Medicina Tropical da Universidade Federal da Paraiba e da SUCAM, Ministério da Saúde, financiando em parte pelo CNPq (PIDE).

Recebido para publicaçāo em 7/4/86. logicamente importantes, educação sanitária e melhoria do saneamento básico e do suprimento de água.

Inicialmente foi feito um inquérito de prevalência entre escolares de 7 a 14 anos de idade, através do exame de fezes, utilizando-se a técnica de Kato-Katz qualitativa, isto é, sem contagem do número de ovos.

Nos municipios onde a prevalência da infecção pelo $S$. mansoni entre os escolares era superior a $20 \%$ toda a população era tratada, excluindo-se os casos de gravidez, doença febril de etiologia desconhecida e doenças crônicas graves; onde a prevalência estava entre 4 e $20 \%$ o tratamento era feito apenas na população de 5 a 25 anos e quando a prevalência era inferior a $4 \%$ entre os escolares, apenas as crianças, cujo exame de fezes era positivo, eram tratadas. 
O controle do tratamento sempre que possivel era feito pelo exame de fezes dos escolares com intervalo de 6 meses a 1 ano, repetindo-se o tratamento de acordo com os critérios acima mencionados. Entretanto, diversas variações foram adotadas ao longo do programa em localidades especificas.

\section{METODOLOGIA DA PRESENTE AVALIAÇÃO}

Inicialmente, em 1984, fizemos uma visita a toda área trabalhada no Estado da Paraiba, em companhia do então Diretor Regional da Superintendência de Campanhas de Saúde Pública (SUCAM), ele é um dos autores, e dos supervisores de áreas, analisando detidamente as peculiaridades de cada uma delas, tipo de intervenção - tratamento, uso de moluscicidas, saneamento, avaliaçōes realizadas e dificuldades encontradas.

Em uma segunda etapa obtivemos na Diretoria Regional da SUCAM na Paraiba, os dados da prevalência inicial da infecção entre os escolares e das sucessivas avaliações realizadas no periodo de 1978 a $1983 \mathrm{em}$ um total de 5. Esses resultados foram colocados em um computador que nos deu uma seqüência da prevalência inicial por municipio das 4 regiōes hidrográficas trabalhadas - região da bacia do Mamanguape com 23 municipios, Curimataú com um município, região do Paraiba com 18 municipios e região Litoral Sul com 5 municípios (Fig. 1), apresentando também em seqüência o resultado das 5 avaliações.

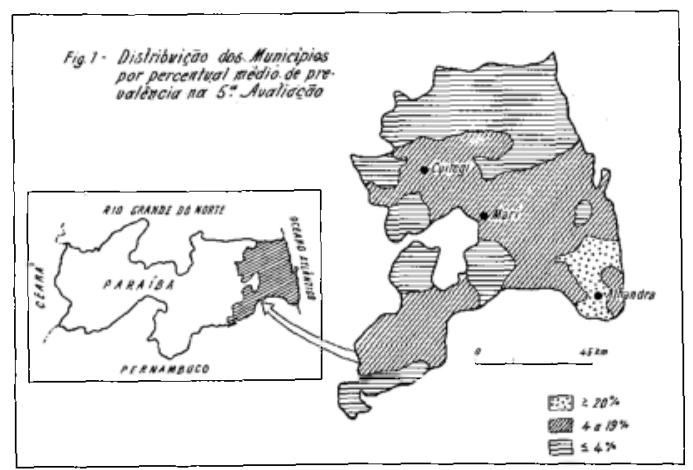

Fig. 1 - Distribuição dos municipios por percentual médio de prevalência na 5.a Avaliação

Como desdobramento da etapa anterior obtivemos ainda a análise comparativa dos resultados da prevalência inicial com os da 5 a avaliação por região hidrográfica e localidade - cidade, vila, povoado, fazenda, engenho, ou sitio, nos quais constava a população alvo, número de exames realizados e número de positivos. Obtivemos ainda informaçōes sobre as espécies de hospedeiro intermediário e os seus indices de infecção.

Diante dos resultados, elegemos ao acaso 3 municípios, um na região da bacia do Mamanguape, outro na região do Paraiba e o terceiro na região Litoral Sul para estudo de uma amostra da população através do exame de fezes quantitativo pelo método de KatoKatz, exame clínico dos casos positivos e exame do hospedeiro intermediario.

Embora somente tivéssemos parâmetros de comparação do exame clínico e quantitativo de fezes no município de Alhandra, na região Litoral Sul, onde foi realizado trabalho anterior ${ }^{15}$ iniciado em 1978 , achamos importante incluir dois outros municipios, o de Cuitegi na região do Mamanguape e o de Mari da região do Paraiba. Dessa forma, além de incluirmos amostras das 3 principais regiões trabalhadas, tivemos a oportunidade de estudar, do ponto de vista clínico e da carga parasitária, uma amostra da população de um município (Cuitegi), onde a prevalência inicial era muito alta $(64,6 \%)$ caindo para $8,5 \%$ na 5 a avaliação, outro (Mari), onde a prevalência inicial era média $(28,3 \%)$ e caiu relativamente pouco $(14,3 \%)$ e finalmente Alhandra, onde a prevalência inicial era alta $(61,5 \%)$ permanecendo ao fim da 5 a avaliação em niveis altos $(26,5 \%)$.

No total dos 3 municípios mencionados foram avaliados pelo exame de fezes quantitativo 9.155 individuos e pelo exame clínico (palpação de figado e baço) 1.036 com exame de fezes positivo.

$\mathrm{Na}$ sede de cada um dos 3 municípios selecionados, Cuitegi na região do Mamanguape, Mari na região do Paraiba e Alhandra na região Litoral Sul, foi delineada uma amostra sistemática por conglomerado de aproximadamente $25 \%$ da população residente para realização do exame de fezes quantitativo, ou seja, toda a familia de uma em cada 4 casas habitadas. $\mathrm{Na}$ zona rural foi realizado o exame de fezes quantitativo da população do sítio Barro Vermelho e do Engenho Livramento em Cuitegi, dos sítios Lagoa do Felix e Mata e das fazendas Jandiroba e Açude Grande em Mari, sítios Tapuiu, Junçara e Sobradinho, fazendas Sabauma e Garupu e do engenho São José em Alhandra. No total foram examinados 3.494 pessoas em Cuitegi, 3.735 em Mari e 1.926 em Alhandra (Tabelas 2, 3 e 4).

\section{RESULTADOS}

Os resultados da prevalência inicial e das 5 avaliações realizadas pela SUCAM entre 1978 e 1983 nos 47 municípios trabalhados estão expostos na Tabela 1. As Figuras 2, 3 e 4 mostram as prevalências iniciais crescentes por municipio e região hidrográfica e comparam essas prevalências em curvas com os resultados obtidos na 1 a e 5 a avaliações.

Nos municipios da região do Mamanguape (Fig. 2) houve uma drástica reduçāo da prevalência da infecção já na 1a avaliação, tanto mais acentuada quanto maior era a prevalência inicial. A prevalência 
Tabela 1 - Distribuição por municipio e região hidrográfica da prevalência inicial (\%) da infecção pelo $\mathrm{S}$. mansoni e das cinco primeiras avaliaçōes do programa PECE no Estado da Paraíba

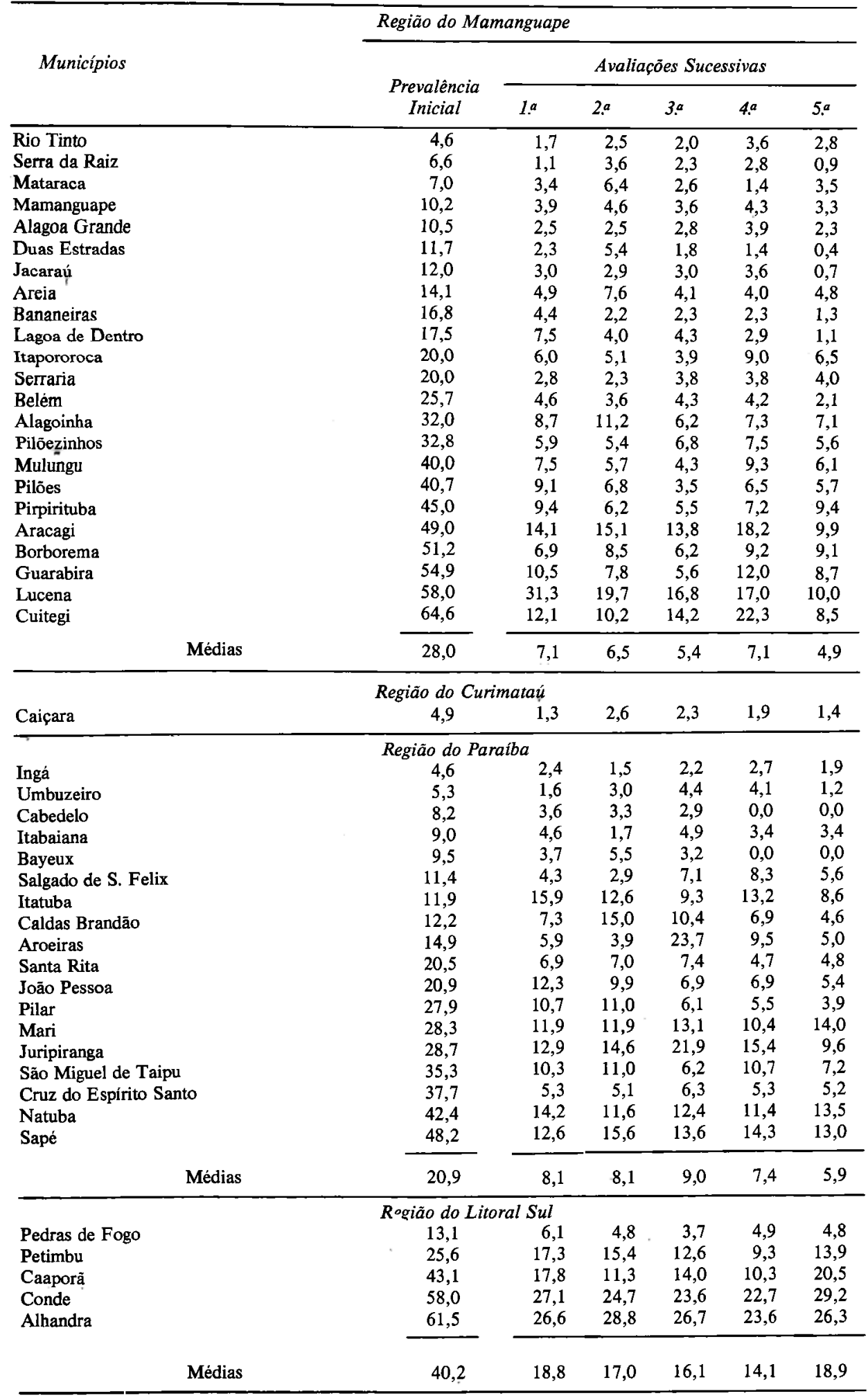

Fonte: SUCAM - Delegacia Regional da Paraiba 

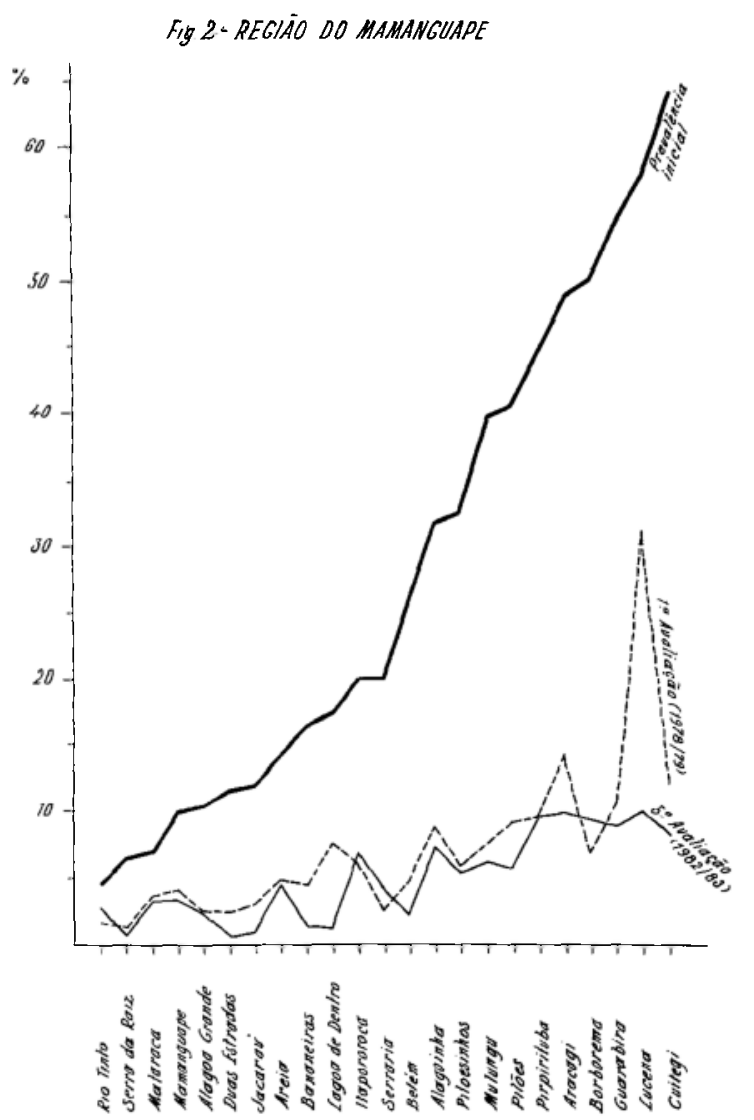

Fig. 2 - Regiāo do Mamanguape

inicial média era de $28 \%$ caindo para $7,1 \%$ na primeira avaliação e para $4,9 \%$ na 5 a avaliação, com pequenas variações entre as demais. Em nível de localidade, entretanto, $36(10,9 \%)$ das 329 avaliadas por coproscopia ainda permaneciam com prevalência igual ou superior a $20 \%$ na 5 a avaliação, as quais foram chamadas por Madruga" ${ }^{14}$ de "localidades-problema".

A região do Curimataú com um único município trabalhado, apresentava uma prevalência inicial de $4,9 \%$ que se reduziu para $1,3 \%$ na 1 a avaliação e $1,4 \%$ na 5 a avaliação.

Nos municípios da região do Paraiba (Fig. 3), com exceçăo de um deles (Itatuba), houve também uma acentuada redução da prevalência da infecção na primeira avaliação em relação à prevalência inicial, redução esta mantida até a 5 a avaliação. A prevalência inicial média era de $20,9 \%$ nessa região caindo para $8,1 \%$ na 1 a avaliação e $5,9 \%$ na 5 a avaliação com variações entre as outras avaliações. A provável explicação para o aumento de prevalência no municipio de Itatuba, após o tratamento, uma vez que a prevalência inicial era de $11,9 \%$, na 1 avaliação $^{\mathrm{a}}$ $15,9 \%$, na 2 a $12,6 \%$, na 3 a $9,3 \%$, na 4 a $13,2 \%$ e na 5 a ainda estava em $8,6 \%$, é a presença de um açude no centro da cidade altamente infestado e com intenso

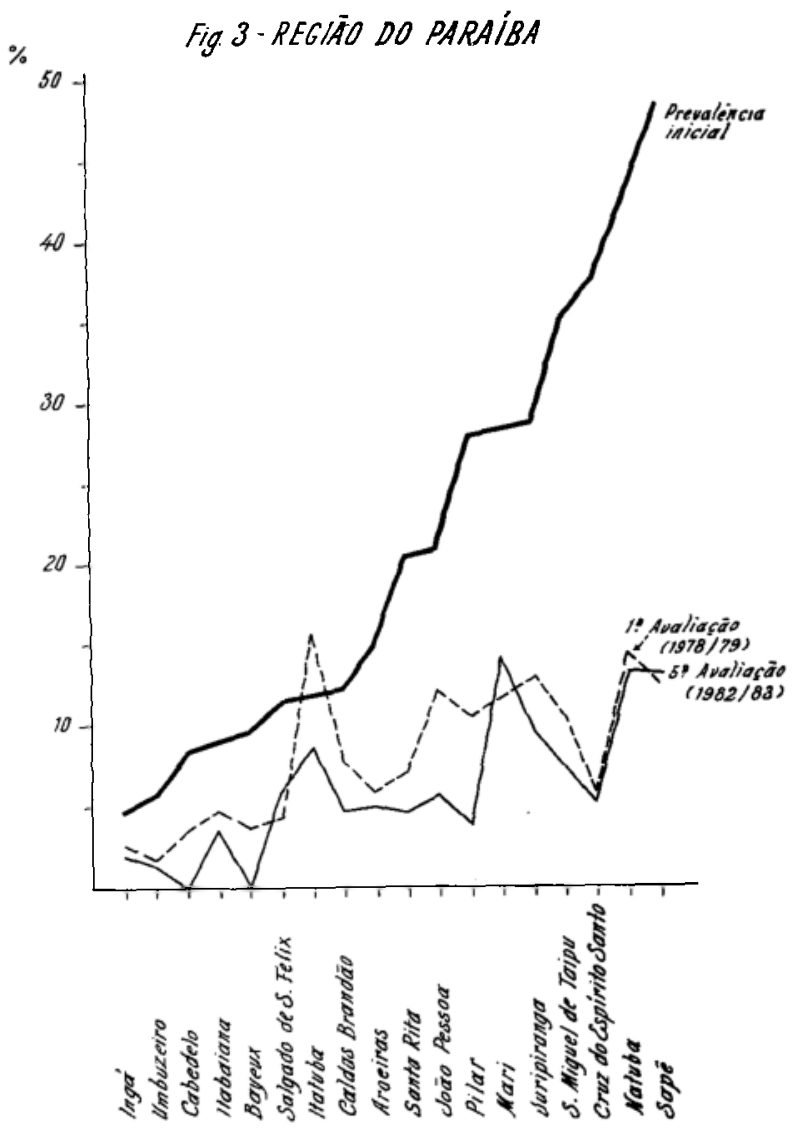

Fig. 3 - Regiāo do Paraíba

contato da população que o utiliza como única fonte de abastecimento de água, lavagem de roupa, banhos, etc. Por outro lado, grande parte da população rural vive às margens do Rio Paraiba, intensamente infestado por caramujos principalmente nos periodos mais secos. Explicação semelhante pode ser aventada para Caldas de Brandão, na mesma região hidrográfica, onde na 2a avaliação ocorreu um aumento da prevalência em relação a inicial (Tabela 1). Embora tenha havido uma importante redução de prevalência da infecção nessa região como um todo, em nivel de localidade $\mathbf{4 0}$ $(13,6 \%)$ das 293 avaliadas ainda apresentavam prevalência entre os escolares igual ou superior a $20 \%$ na 5 a avaliação ${ }^{14}$.

Nos municípios da região Litoral Sul principalmente nos de prevalência inicial mais eleva$\mathrm{da}$, a redução da prevalência após o tratamento não foi tão significativa como nos das demais regióes. A prevalência inicial média dessa região era de $40,2 \%$, caindo apenas para $18,8 \%$ na 1 a avaliação e mantendo-se ainda em 18,9\% na 5: avaliação. Das 91 localidades avaliadas por coproscopia nessa região 43 $(47,2 \%)$ ainda tinham prevalência igual ou superior a $20 \%$ na 5 ! avaliação ${ }^{14}$.

Nos municipios selecionados para a presente avaliação verificou-se uma prevalência de $4,4 \%$ de 


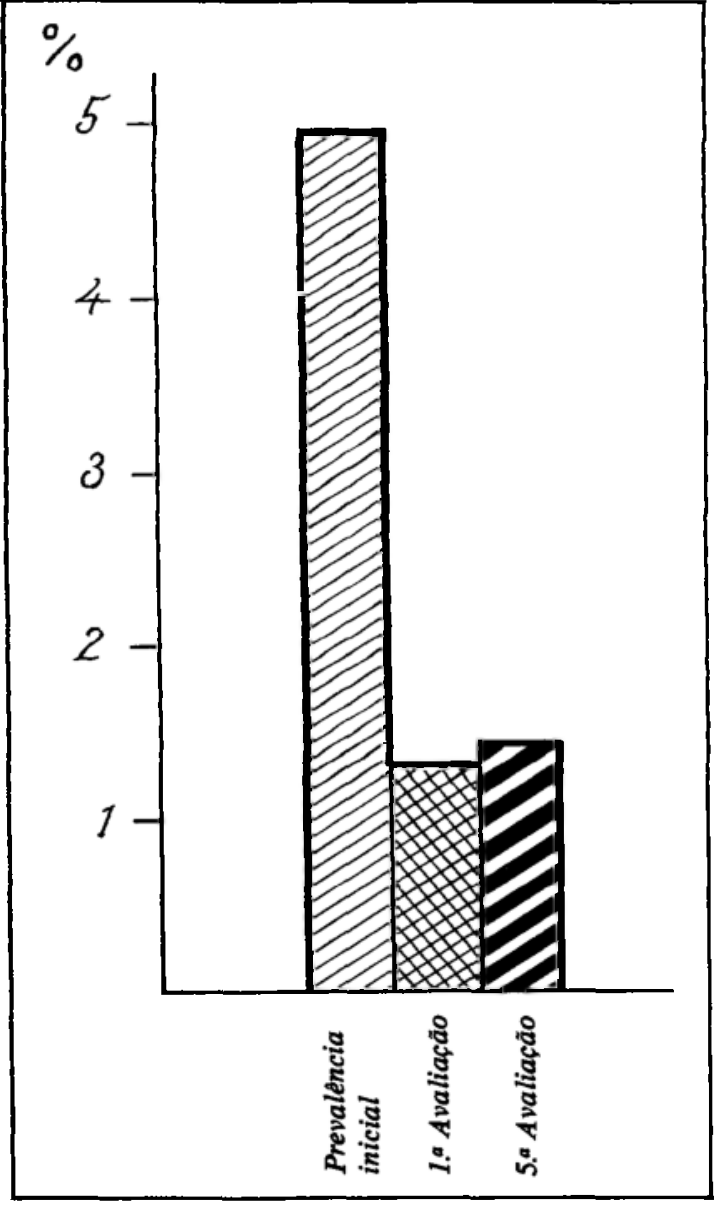

Fig. 4-Região Curimataú - Caiçara

infecção pelo $S$. mansoni em Cuitegi com média de 123 ovos por grama de fezes e mediana de 48; em Mari a prevalência foi de $10,9 \%$ e a média de ovos de $S$. mansoni por grama de fezes foi de 165,9 com uma mediana de 72 e em Alhandra a prevalência foi de $24,5 \%$, a média de 115,4 e a mediana de 48 ovos por grama de fezes (Tabelas 2, 3 e 4). Não se verificou, portanto, uma correlação entre a prevalência da infecção e a carga parasitária nas 3 áreas, como pode ser verificado na Figura 5.

Quanto às formas clínicas, não encontramos nenhum caso da forma hepatoesplênica (III) em Cuitegi e apenas 20 pacientes (12,9\%) entre os 154 com exame de fezes positivos, examinados clinicamente, tinham figado palpável. Em Mari dos 410 pacientes com exame de fezes positivos encontramos apenas um com a forma hepatoesplênica $(0,24 \%)$ e 48 $(11,7 \%)$ com a forma II (hepatointestinal). Já em Alhandra, dos 472 pacientes com exame de fezes positivo examinados clinicamente, encontramos 17 hepatoesplênicos $(3,6 \%)$ e $81(17,1 \%)$ hepatointestinais. Entre 60 e $80 \%$ dos individuos a forma hepatointestinal nas 3 áreas ocorreu em menores de 20 anos,

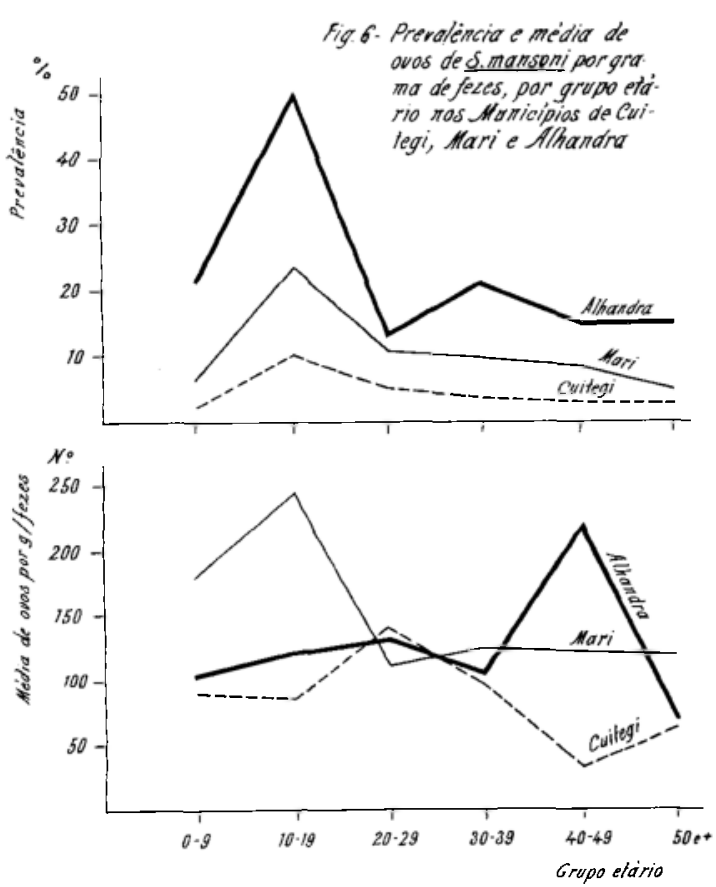

Fig. 5 - Prevalência e média de ovos de S. mansoni porgrama de fezes, por grupo etário nos Municipios de Cuitegi, Mari e Alhandra.

enquanto em Alhandra todos os 17 casos da forma hepatoesplênica tinham mais de 30 anos de idade, fato já assinalado em trabalhos anteriores 715 .

Foi impossível uma avaliação correta do controle de caramujos e das obras de saneamento realizadas, dadas a extensão das áreas e a irregularidade das medidas aplicadas em cada uma delas. Verificamos com freqüência a presença de Biomphalaria straminea e $\boldsymbol{B}$. glabrata, esta última espécie nos municípios de Lucena e Alhandra, onde encontramos exemplares infectados com S. mansoni. Entre 1976 e 1980 a Fundaçāo Serviços de Saúde Pública (FSESP) instalou apenas 14.717 privadas, 11.512 banheiros, 12.568 tanques de lavar roupa e fez melhoria em 38.797 instalações, o que nos pareceu muito pouco em relação à extensão e à população da área endêmica.

\section{DISCUSSÃO}

O próprio título do presente trabalho "Tentativa de avaliação..." já define as dificuldades encontradas nessa tarefa, principalmente pela forma como foi elaborado o PECE e como vem sendo executado. Primeiramente a determinação da prevalência em escolares de 7 a 14 anos não representa necessariamente a prevalência na população geral. Em segundo lugar a falta do exame quantitativo das fezes e do exame clinico antes do inicio do tratamento nos deixa sem dois parâmetros extremamente importantes para avaliação da redução da carga parasitária e da gravidade das formas clínicas após o tratamento. Por outro 
Coura JR, Mendonça ZG, Madruga JP. Tentativa de avaliaçāo do Programa Especial de Controle da Esquistossomose (PECE) no Estado da Parába, Brasil. Revista da Sociedade Brasileira de Medicina Tropical 20: 67-76, Abr-Jun, 1987.

Tabela 2 - Distribuiçâo da prevalência da infeç̧ão, média e mediana do no de ovos de S. mansoni por grupo etário em uma amostra da população de Cuitegi, no Estado da Paraíba, 1984

\begin{tabular}{|c|c|c|c|c|c|}
\hline \multirow{2}{*}{$\begin{array}{c}\text { Grupo etário } \\
\text { (anos) }\end{array}$} & \multirow{2}{*}{$\begin{array}{c}\text { No de pessoas } \\
\text { submetidas ao } \\
\text { exame de } \\
\text { fezes }\end{array}$} & \multicolumn{2}{|c|}{ Prevalência } & \multicolumn{2}{|c|}{$\begin{array}{l}\text { No de ovos de } \mathbf{S} \text {. } \\
\text { mansoni por } g / \text { fezes }\end{array}$} \\
\hline & & No Positivo & $\%$ & Média & Mediano \\
\hline $0-9$ & 960 & 23 & 2,3 & 90,7 & 48 \\
\hline $10-19$ & 501 & 51 & 10,1 & 87,3 & 48 \\
\hline $20-29$ & 568 & 31 & 5,4 & 139,5 & 48 \\
\hline $30-39$ & 450 & 16 & 3,5 & 96,5 & 48 \\
\hline $40-49$ & 375 & 12 & 3,2 & 34,0 & 48 \\
\hline 50 e + & 640 & 21 & 3,2 & 63,2 & 24 \\
\hline Total & 3.494 & 154 & 4,4 & 123,0 & 48 \\
\hline
\end{tabular}

Tabela 3 -Distribuição da prevalência da infeçâo, média e mediana do no de ovos de S. mansoni por grupo etário, em uma amostra da população de Mari, no Estado da Paraíba, 1984

\begin{tabular}{|c|c|c|c|c|c|}
\hline \multirow{2}{*}{$\begin{array}{c}\text { Grupo etário } \\
\text { (anos) }\end{array}$} & \multirow{2}{*}{$\begin{array}{l}\text { No de pessoas } \\
\text { submetidas ao } \\
\text { exame de } \\
\text { fezes }\end{array}$} & \multicolumn{2}{|c|}{ Prevalência } & \multicolumn{2}{|c|}{$\begin{array}{l}\text { No de ovos de } \mathrm{S} \text {. } \\
\text { mansoni por } \mathrm{g} / \text { fezes }\end{array}$} \\
\hline & & No Positivo & $\%$ & Média & Mediano \\
\hline $0-9$ & 959 & 64 & 6,6 & 179,0 & 96 \\
\hline $10-19$ & 724 & 174 & 24,0 & 245,0 & 72 \\
\hline $20-29$ & 594 & 64 & 10,7 & 107,8 & 48 \\
\hline $30-39$ & 445 & 44 & 9,8 & 124,5 & 72 \\
\hline $40-49$ & 405 & 35 & 8,6 & 116,0 & 24 \\
\hline $50 e+$ & 608 & 29 & 4,7 & 120,0 & 72 \\
\hline Total & 3.735 & 410 & 10,9 & 165,9 & 72 \\
\hline
\end{tabular}

Tabela 4 - Distribuição da prevalência da infeç̧ão, média e mediana do no de ovos de S. mansoni por grama de fezes por grupo etário em amostra da população de Alhandra, Estado da Paraíba, 1984

\begin{tabular}{|c|c|c|c|c|c|}
\hline \multirow{2}{*}{$\begin{array}{c}\text { Grupo etário } \\
\text { (anos) }\end{array}$} & \multirow{2}{*}{$\begin{array}{l}\text { No de pessoas } \\
\text { submetidas ao } \\
\text { exame de } \\
\text { fezes }\end{array}$} & \multicolumn{2}{|c|}{ Prevalência } & \multicolumn{2}{|c|}{$\begin{array}{l}\text { No de ovos de } \mathrm{S} \text {. } \\
\text { mansoni por g/fezes }\end{array}$} \\
\hline & & No Positivo & $\%$ & Média & Mediana \\
\hline $0-9$ & 620 & 136 & 21,9 & 103,2 & 48 \\
\hline $10-19$ & 374 & 187 & 50,0 & 120,1 & 48 \\
\hline $20-29$ & 286 & 37 & 12,9 & 130,6 & 72 \\
\hline $30-39$ & 229 & 48 & 20,9 & 101,3 & 48 \\
\hline $40-49$ & 183 & 28 & 15,3 & 215,7 & 48 \\
\hline 50 e + & 234 & 36 & 15,3 & 68,0 & 48 \\
\hline Total & 1.926 & 472 & 24,5 & 115,4 & 48 \\
\hline
\end{tabular}

lado o tratamento dos escolares de 7 a 14 anos que serviram como grupo controle para as reavaliações inferidas para a população geral deve ter sido muito mais completo do que na população adulta cujo tratamento deve ter sido mais limitado devido às contraindicações como gravidez, doenças crônicas, ausências e migrações mais freqüentes entre os adultos. A limitação do tratamento dos grupos etários entre 5 e 25 anos de idade quando a prevalència inicial ou as avaliações estavam entre 4 e abaixo de $20 \%$ e o tratamento apenas dos infectados quando a prevalência estava abaixo de $4 \%$ dos escolares é outro fator limitante para avaliação dos resultados sobre a população geral. 
Embora reconheçamos as imprecisōes apontadas, também reconhecemos as dificuldades da realização de um programa dessa extensão e natureza para a aplicação de critérios perfeitos de avaliação. Acreditamos, porém, que se tivesse sido definida uma amostra por conglomerado representativa da população residente de cada localidade para o exame de fezes quantitativo e de uma pequena parcela da população a ser tratada em cada municipio com exame clinico antes do tratamento, teríamos parâmetros muito mais perfeitos para avaliaçāo e modificações futuras do programa.

Acreditamos também que os objetivos iniciais de "eliminação da transmissão e redução da prevalência a menos de 4\%" foram extremamente ambiciosos para um programa dessa extensão e complexidade e portanto inatingiveis. Para reforço dessa afirmação basta considerarmos os seguintes fatores: a) impossibilidade do controle definitivo do hospedeiro intermediário em extensas áreas de contato da população; b) impossibilidade de evitar o contato da população com a água infestada; c) impossibilidade do tratamento e cura simultânea de toda a população infectada, por falha terapêutica (superior a 10\%), contra-indicaçōes, ausências, etc.; d) impossibilidade de evitar o contato dos dejetos humanos com a água infestada: ausência de privadas nas áreas de trabalho no campo, não uso ou uso inadequado das privadas existentes; e) grande dinâmica da infecção: milhões de cercárias desenvolvidas nos hospedeiros intermediários em contato com apenas alguns poucos miracídios, entre outros fatores.

Apesar das restrições mencionadas diversos trabalhos realizados no Brasil entre os quais os de Maciel $^{13}$, Jansen $^{8}$, Sette ${ }^{21}$, Silva ${ }^{21}{ }^{22}$, Kloetzel ${ }^{11} 12$, Bina e Prata ${ }^{2} 3$, Katz e cols. ${ }^{9}$ 10, Coura e cols. ${ }^{5} 6$, Prata ${ }^{16}$, Bina ${ }^{1}$, Santos ${ }^{18}$ e Prata e cols..$^{17}$ entre outros, têm mostrado resultados favoráveis quanto à redução da prevalência, da carga parasitária e da morbidade da doença em maiorou menor grau, de acordo com a droga utilizada, condições da população submetida ao tratamento e tempo de observação. Nas áreas endêmicas houve sempre uma tendência à reinfecção progressiva principalmente nos grupos mais jovens, embora a carga parasitária se mantenha baixa a médio prazo em relação a de antes do tratamento. Em trabalho recente do tipo caso-controle em uma área hiperendêmica, Santos e Coura ${ }^{19}$ verificaram com tratamento único pela oxamniquine uma drástica redução da prevalência e da carga parasitária no primeiro ano, as quais voltaram a niveis próximos dos iniciais ao final do sexto ano de observação, havendo agravamento da doença tanto no grupo tratado como no grupo-controle, embora com maior tendência de agravamento neste último.

Indubitavelmente houve uma expressiva redução da prevalência da infecção esquistossomótica nas
4 regiões endêmicas do estado da Paraiba após os trabalhos iniciais do PECE, o que pode ser verificado pela análise da Tabela 1 e das Figuras 2, 3 e 4.

Entretanto essa redução não se mostrou progressiva ao longo dos 5 tratamentos e avaliações realizadas, como demonstram as médias da Tabela 1 , indicando talvez a inoperância dẹ tratamentos freqüentes a intervalos de 6 meses a um ano, o que nos leva a crer que com tratamentos mais espaçados, com dois a três anos de intervalo poderíamos obter resultados semelhantes, com menor custo e possibilidade de melhor avaliação.

Ainda com referência à redução da prevalência houve importantes diferenças regionais. Se tomarmos como parâmetros as prevalências médias inicial e a da 5a avaliação verificamos que na região do Mamanguape a redução foi de 5,7 vezes, na Curimataú foi de 3,5, na região do Paraiba foi também de 3,5 vezes enquanto no Litoral Sul a redução foi apenas de 2,1 vezes, em relação a prevalência inicial. Também houve variações intra-regionais ou intermunicipais $\mathrm{e}$ intramunicipais (locais). Dessa forma verificamos que $10,9 \%$ das localidades da região do Mamanguape ainda apresentavam na 5 a avaliação prevalências superiores a $20 \%$ enquanto a prevalência média da região era de $4,9 \%$ nessa época, fato que se repetiu na região do Paraíba com $13,6 \%$ e na região Litoral Sul com $47,2 \%$ de localidades com $20 \%$ ou mais de prevalência na 5 a avaliação enquanto as prevalências médias eram respectivamente de 5,9 e $18,9 \%$ para essas regiões na 5 a avaliação. Esse fato demonstra que a dificuldade de controle da esquistossomose é mais de origem local, como por exemplo maior contato da população com a água, espécie e índices de infecção dos hospedeiros intermediários, dependentes da intensidade do contato com fezes contaminadas com ovos de S. mansoni e da adaptação do vetor ao tipo de cepa parasitária.

Embora não tenhamos parâmetros de comparação antes do tratamento para 2 dos 3 municipios selecionados para o estudo especial de avaliação, verificamos que em Cuitegi na região do Mamanguape a prevalència por nós encontrada na amostra da população geral foi de $4,4 \%$, semelhante a encontrada pela SUCAM na 5: avaliação entre os escolares de 7 a 14 anos. A baixa de 5,7 vezes em relação a prevalência inicial, encontrada pela SUCAM durante a 5 a avaliação, a ausência de casos da forma hepatoesplênica e de apenas $12,9 \%$ de indivíduos com o figado palpável em $154 \mathrm{com}$ exame de fezes positivo examinados clinicamente, aliados a uma carga parasitária baixa ( 123 de média e 48 de mediana de ovos de $S$. mansoni por grama de fezes) indica a benignidade atual da doença na área. Já em Mari a prevalência por nós encontrada na população geral foi de $10,9 \%$ inferior a encontrada pela SUCAM na 5a avaliação entre os escolares 
(14\%), porém bem superior a média da região nessa avaliação que foi de $5,9 \%$. Esse dado, aliado ao encontro de uma média de 165,9 e mediana de 72 ovos de $S$. mansoni por grama de fezes, indica uma área potencialmente de maior gravidade futura da doença, embora apenas um caso $(0,24 \%)$ da forma hepatosplênica e $48(11,7 \%)$ da forma hepatointestinal tenham sido encontrados nos 410 pacientes com exames de fezes positivos para $S$. mansoni examinados clinicamente. Convém lembrar que nessa área a redução da

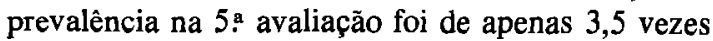
menor do que a prevalência inicial. Em Alhandra, na região Litoral Sul, a gravidade da doença é bem superior. Embora a contagem de ovos seja relativamente baixa (115,4 de média e 48 mediana de ovos de S. mansoni) em 472 casos positivos, a prevalência foi de $24,5 \%$, nunca se tendo obtido níveis abaixo desses durante as 5 avaliações (Tabela 1), mostrando, portanto, uma transmissão contínua e permanente, também confirmado pelo baixo potencial de redução entre a prevalência inicial médic da área e a 5 a avaliação, igual a 2,1 vezes para a região e 2,3 vezes para Alhandra. Por outro lado, o elevado número de 17 casos $(3,6 \%)$ da forma hepatoesplênica encontrado e 81 de forma hepatointestinal $(17,1 \%)$ em crianças e jovens abaixo de 20 anos mostra o potencial evolutivo da infecção e da doença na área. É certo que todos os casos da forma hepatoesplênica foram observados em maiores de $\mathbf{3 0}$ anos de idade, o que aliás tem sido um padrão dessa região como demonstramos em trabalhos anteriores $^{7} 15$. Em um estudo realizado na sede do município de Alhandra em 1979, verificamos que $24,2 \%$ da população era positiva para $S$. mansoni, eliminando em média 211 ovos por grama de fezes; $\mathbf{2 , 4 \%}$ eram portadores da forma hepatoesplênica $\mathrm{e}$ apenas $3 \%$ tinham o figado palpável.

A presença da B. glabrata como principal vetor no município de Alhandra e a intensidade do contato da população com a água, talvez expliquem os altos níveis de prevalência da infecção e morbidade da doença nessa área e na região como um todo. Embora praticamente todas as casas da área urbana desse município sejam providas de privadas, a falta do uso ou o uso inadequado, parece não ter alterado muito a dinâmica de transmissão da doença na área.

Em estudo de reavaliação da área urbana de Alhandra após 5 anos, Mendonça ${ }^{15}$ verificou que a redução da prevalência da esquistossomose foi de apenas $12 \%$, que não houve redução da gravidade da doença e que a prevalència das parasitoses intestinais pouco se reduziu nesse período, apesar da existência de privadas em quase todas as residências.

Finalmente concluímos que o programa foi relativamente eficaz para reduzir a prevalência da infecção pelo $S$. mansoni e possivelmente para reduzir a morbidade da doença nas regiões do Mamanguape, do Paraiba, e do Curimataú, mas foi pouco eficaz para reduzir a prevalência na região Litoral Sul, não se alterando ou até mesmo agravando-se a morbidade da doença no município de Alhandra tomado como parâmetro dessa região.

Recomendamos as seguintes modificações para maior amplitude, eficácia e redução do custo do programa: 1) que os tratamentos sejam feitos a intervalos de 2 a 3 anos e que a eles se associem um polihelmintico de largo espectro do tipo mebendazole, tendo em vista a freqüência e gravidade de outras helmintiases concomitantes com a esquistossomose, 2) que as avaliações sejam feitas na população geral, com contagem de ovos de $S$. mansoni, a intervalos também de 2 a 3 anos, seguidas imediatamente pelo tratamento, ou seja, a proporção que uma equipe faz 0 exame de fezes em uma localidade outra equipe trata imediatamente os casos positivos; 3) que seja dado prioridade ao abastecimento de água através de um sistema simplificado no qual se coloque pelo menos uma torneira abastecida continuamente nos fundos de cada casa; 4) que os moluscicidas sejam restritos a focos particulares do tipo pequenas coleçōes de água de alto contato da população; 5) que seja feita uma contínua mobilização da população através das escolas, postos de saúde e prefeituras para esclarecimento, tratamento e prevenção não somente da esquistossomose, mas de todas as doenças evitáveis.

\section{SUMMARY}

An attempt was made to evaluate the efficacy of the Special Programme for Schistosomiasis Control (PECE) carried out in the state of Paraiba since 1976 by Superintendência das Campanhas de Saúde Pública (SUCAM), Ministry of Health of Brazil. The evaluation was based on five stool examinations done by SUCAM in the school children of the endemic area from 1978 to 1983 and on a clinical and quantitative stool examination performed in 1984 and 1985 in a sample of 9155 persons living in three selected municipalities each one in a different region of the endemic area: Mamanguape, Paraíba and Litoral Sul.

The stool examinations performed from 1978 to 1983 showed a drop of $\mathrm{S}$. mansoni infection from $28 \%$ to $4.9 \%$ in Mamanguape, $20.9 \%$ to $5.9 \%$ in Paraiba $40.2 \%$ to $18.9 \%$ in Litoral Sul and $4.9 \%$ to $1.4 \%$ in Curimatau. At the local level, however, the prevalence of the infection in 1983 was $20 \%$ or higher in 36 (10.9\%) of 329 localities evaluated in Mamanguape, 40 (13.6\%) of 293 in Paraiba and 43 (47.2\%) of 91 localities of Litoral Sul. 
The sample of the population submitted to clinical and a quantitative stool examination showed $4.4 \%$ passing an average of 123 eggs of $\mathrm{S}$. mansoni per gram of feces in Mamanguape where $12.9 \%$ of the positive cases had a palpable liver and none had the hepatosplenic form of the disease. In Paraiba $10.9 \%$ of the sample was positive for $\mathrm{S}$. mansoni, with an average of 165.9 eggs per gram of feces; $11.7 \%$ of the positives had a palpable liver and only one $(0.24 \%)$ had the hepatosplenic form. In Litoral Sul $24.5 \%$ of the sample passed an average of 115.4 eggs per gram of feces, $17.1 \%$ of the positives had a palpable liver and $3.6 \%$ had the hepatosplenic form of the disease.

The authors conclude that the programme was able to reduce the prevalence of the infection and possibly to reduce the morbidity of the disease in Mamanguape, Paraíba and Curimataú, but was less efficient in reducing the prevalence of infection and unable to reduce the morbidity of the disease in the population of Litoral Sul.

Key words: Schistosomiasis. Control. Mass treatment. Brasil.

\section{AGRADECIMENTOS}

Os autores agradecem aos Drs. José Sales Pires da SUCAM e Sônia Maria Silva do Núcleo de Medicina Tropical da UFPb pela inestimável ajuda no trabalho de campo e aos Srs. Jorge Ayres e Joel Antunes, respectivamente pelos trabalhos de computação e desenhos.

\section{REFERÊNCIAS BIBLIOGRÁFICAS}

1. Bina JC. Influência da terapêutica especifica na evolução da esquistossomose mansoni. Tese, Universidade Federal da Bahia, Salvador, 1977.

2. Bina JC, Prata A. Hycanthone no tratamento da esquistossomose em uma área rural com baixo indice de transmissão da doença. Gazeta Médica da Bahia 70:127-130, 1970.

3. Bina JC, Prata A. An attempt to control schistosomiasis mansoni in an endemic area by the use of Hycanthone as chemotherapeutic agent. Revista da Sociedade Brasileira de Medicina Tropical 8:217-222, 1974.

4. Brasil, Ministério da Saúde. Programa Especial de Controle da Esquistossomose (PECE). Brasilia, 1 a 5 de agosto de 1977.

5. Coura JR, Wanke B, Figueiredo N, Argento CA. Evolutive pattern of schistosomiasis and life-span of $S$. mansoni in patients living in non-endemic area in Brazil. Revista da Sociedade Brasileira de Medicina Tropical 8:193-198, 1974.

6. Coura JR, Argento CA, Conceição MJ, Lewis EM, Santos ML, Magalhães P. Experiências de campo com oxamniquine oral no tratamento da esquistossomose mansoni. Revista do Instituto de Medicina Tropical de Sảo Paulo 22 (Supl. 4): 77-84, 1980.
7. Coura JR, Conceição MJ, Menezes AP, Santos ML, Mendonça MZ. Morbidade da Esquistossomose mansoni no Brasil. II - Estudo em quatro áreas de campo nos estados de Minas Gerais, Sergipe e Paraiba. Memórias do Instituto Oswaldo Cruz 78:1-11, 1983.

8. Jansen G. Profilaxia experimental da esquistossomose de Manson. Memórias do Instituto Oswaldó Cruz 44:549-578, 1946.

9. Katz N, Antunes CMF, Andrade RM, Coelho PMZ. An attempt to control schistosomiasis mansoni in an endemic area by combining clinical treatment and molluscicide application. Journal of Parasitology (Section II) 56:435, 1970.

10. Katz N, Rocha RS, Pereira JP. Schistosomiasis control in Peri-Peri (Minas Gerais, Brazil) by repeated clinical treatment and molluscicide application. Revista do Instituto de Medicina Tropical de São Paulo 22(Supl. 4): 8593, 1980.

11. Kloetzel K. Sobre a conveniência da quimioterapia em população em contínuo contato com os focos (Nota prévia). Revista do Instituto de Medicina Tropical de São Paulo 5:106-110, 1963.

12. Kloetzel K. A suggestion for the prevention of severe clinical forms of schistosomiasis mansoni. Bulletin of the World Health Organization 37: 686-687, 1967.

13. Maciel $\mathrm{H}$. $\mathrm{O}$ tratamento da schistosomose intestinal no Hospital da Marinha. Sciencia Médica 7:20-24, 1929.

14. Madruga JP. Relatório apresentado na Reuniāo das Diretorias Regionais da SUCAM da Região Nordeste sobre o Programa Especial de Controle da Esquistossomose (PECE). Recife 3 a 6 de julho de 1984.

15. Mendonça MZG. Estudos sobre a Esquistossomose mansoni em Alhandra, Estado da Paraiba. Tese, Universidade Federal do Rio de Janeiro, 1982.

16. Prata A. Experiences in Brazil with the use of available schistosomicides in mass treatment campaigns. Revista da Sociedade Brasileira de Medicina Tropical 10:355-360, 1976.

17. Prata A, Bina JC, Barreto AC, Alecrim MG. Attempt to control the schistosomiasis transmission by oxamniquine in an hyperendemic locality. Revista do Instituto de Medicina Tropical de São Paulo 22 (Supl. 4):65-72, 1980.

18. Santos ML. Esquistossomose mansoni. Estudo da morbidade e interferência da terapêutica específica em uma área endêmica. Tese. Universidade Federal do Rio de Janeiro, Rio de Janeiro, 1978.

19. Santos ML, Coura JR Morbidade da Esquistossomose no Brasil. IV - Evolução em pacientes tratados e seus controles. Memórias do Instituto Oswaldo Cruz 81:53$60,1986$.

20. Sette H. Tratamento da esquistossomose mansoni à luz .da patologia hepática (Estudo clínico). Tese, Faculdade de Medicina de Recife, Recife, 1953.

21. Silva JR. Valor e importância do tratamento específico da esquistossomose mansoni no campo da profilaxia. Revista Brasileira de Medicina 14:524-526, 1957.

22. Silva JR. Estado atual e perspectivas da quimioterapia especifica na esquistossomose mansoni. Jornal Brasileiro de Medicina 3:1-14, 1960. 